\title{
How the Maastricht criteria and the Stability and Growth Pact affected real convergence in the European Union A panel data analysis
}

\author{
Elias Soukiazis*, Vítor Castro \\ Faculty of Economics, University of Coimbra, Av. Dias da Silva, 165-3004-512 Coimbra, Portugal
}

Available online 19 January 2005

\begin{abstract}
The European Central Bank (ECB) monetary policy has been criticised for giving more attention to price stabilisation in Europe rather than encouraging higher growth and employment. It is now largely accepted that the Maastricht norms reinforced by the Stability Pact have imposed serious macroeconomic constraints on economic performance by not taking into account specific problems of the individual economies. An interesting issue to examine is how the Maastricht obligations and the Stability Pact restrictions have affected the process of real convergence between the European economies in the last two decades. The purpose of this paper is to test for convergence in living standards, productivity, investment and unemployment among the European countries. From this analysis and using panel data estimation techniques, it is possible to detect any significant influence (favourable or not) of the Maastricht rules on real convergence.

(c) 2005 Society for Policy Modeling. Published by Elsevier Inc. All rights reserved.
\end{abstract}

JEL classification: $\mathrm{C} 23 ; \mathrm{H} 6 ; \mathrm{O} 47$

Keywords: Maastricht criteria; Stability and Growth Pact; Sigma convergence; Absolute and conditional convergence; Panel data regressions

* Corresponding author.

E-mail addresses: elias@fe.uc.pt (E. Soukiazis),vcastro@fe.uc.pt (V. Castro). 


\section{Introduction}

The Maastricht Treaty came into force in 1992 and represented the first great step toward the creation of an Economic and Monetary Union (EMU) in Europe. The countries that signed the Treaty had to accomplish some monetary criteria in order to be accepted as members of the EMU. These criteria were established in order to achieve nominal convergence (and attenuate asymmetric shocks) reducing, therefore, the economic disparities that existed between the European Union (EU) countries before the creation of the EMU in 1999. Having committed themselves to these criteria, the countries involved surrendered a degree of their national sovereignty to the monetary authorities of the EMU, and lost a great deal of flexibility at economic policy level. By 1999, they had further lost all control over the exchange rate and monetary policies with their adhesion to the EMU. The European Central Bank (ECB) is now having a total control of these policies. The only independent policy available to the members is fiscal policy, but even this is limited by the requirements of the Stability and Growth Pact, which aims to guarantee the equilibrium of public finances, avoid inflationary pressures, and promote economic growth in the euro area. Despite its relative success in controlling public deficits and achieving price stability in the Euro area, there are no signs of a sound economic recovery and employment achievements.

The Stability Pact introduced in 1997, was designed to achieve price stability and sustainable growth in the long-term for members of the euro zone. Its main argument is to achieve zero public deficits in the medium-term with the aim of producing greater budget flexibility when members suffer asymmetric shocks and fall into recession. A balanced public budget allows economic adjustments to be made in the short-term, when the economies involved are affected by asymmetric shocks, without disturbing price stability. In the absence of the exchange rate mechanism and a centralized budget system at the EU level, national government budgets are the only available means for state members to cope with asymmetric shocks. National budgets have to play the role of automatic stabilizers when an economy is hit by recession. This is the main reason of the existence of the Stability Pact: it gives the members of a monetary union more room of manoeuvre and compensates them for the loss of both monetary independence and exchange rate policy.

The Maastricht criteria regarding nominal convergence and the Stability Pact requirements made on public deficits have imposed some important constraints which can be neither favourable to growth nor to employment performance. On the other hand, the EMU monetary authorities have shown to be more concerned with maintaining price stability than with promoting growth and investment or reducing unemployment in Europe. Statistical evidence from the last decade shows that since the imposition of the Maastricht norms in 1992, economic growth in Europe has been modest and unemployment does not show a significant recovery. This poor performance is especially true since 2001 and many economists agree that Europe is remaining into recession and the recovery signs are very weak. ${ }^{1}$ This paper tries to show how these monetary rules affected real convergence in Europe, in particular, whether living standards, productivity, investment decisions and employment, have been influenced favourably or not by the Maastricht rules.

\footnotetext{
${ }^{1}$ Recent statistical data from Eurostat shows that the euro zone grew at a rate of less than $1 \%$ per year during the last 5 years.
} 
The rest of the paper is divided in the following parts: Section 2 examines briefly the theoretical aspects of the convergence processes which are mainly used in growth empirics. Section 3 presents the estimated convergence equations on per capita income, productivity, investment and unemployment and discusses the obtained results. The Maastricht criteria (among other basic factors) are used in the extended growth equations as conditioning factors in order to identify any favourable (or not) influence on real convergence. Section 4 accesses the main conclusions from the convergence process in the EU and the impact of the Maastricht policy settings on the behaviour of the variables that characterise real convergence.

\section{The concepts of convergence}

The issue of economic convergence has become the centre of attraction in the growth literature during the last decade. In Europe, this issue became particularly interesting after the creation of the monetary union in 1999 and with the importance attached to economic and social cohesion. Structural funds and cohesion policies became important instruments in reducing regional disparities in the EU.

A plethora of empirical work has appeared testing the convergence issue, mostly focussed on real convergence referring to per capita income as a measure of living standards, or product per worker as a measure of labour productivity. The popular approaches which are used explore the concepts of $\sigma$-(sigma) and $\beta$-(beta) convergence, the former measuring the dispersion of per capita income or productivity among different economies (regions or countries) over time and the latter predicting the inverse relationship between the growth of per capita income or productivity and their initial levels. The $\sigma$-convergence or variance convergence ${ }^{2}$ implies that wealth differences are diminishing among a set of countries or regions over time. The evidence of $\sigma$-sigma convergence is useful, since one can observe periods of convergence or divergence through time. The evidence of $\beta$-convergence or regression convergence is different, showing directly the rate of convergence across economies, implying that poor regions or countries grow faster than richer ones. The two measures are complementary, but not excludable: $\beta$-convergence is a necessary, but not a sufficient condition, for $\sigma$-sigma convergence to take place (Sala-i-Martin, 1996).

The concept of $\beta$-convergence is further used to predict absolute and conditional convergence. Absolute (or unconditional) convergence is the idea that comes out of standard neoclassical growth theory based on diminishing returns to capital properties (Solow, 1956). According to the neo-classical theory, convergence is the rule and divergence is a transitory short-term phenomenon. Free trade and perfect factor mobility will guarantee the convergence result through the equalisation of factor prices. Exogenous technical progress is treated as a public good freely available to the poor regions facilitating the imitation process and allowing them to grow faster. Under these circumstances, policies have no role in shaping long-term economic growth. Empirical studies give support to the absolute convergence hypothesis only as a special case where the sample involves economies with a

\footnotetext{
${ }^{2}$ For this definition, see Sala-i-Martin (2003).
} 
high degree of homogeneity. This is known as the convergence club hypothesis (Chatterji, 1992).

Conditional convergence, on the other hand, comes out of "new" endogenous growth theory, which emphasises the importance of human capital and innovation as the conditioning factors to convergence (Barro, 1991). The theory relaxes the assumption of diminishing returns to reproducible factors and states the possibility of constant or even increasing returns to scale emanating from human and physical capital accumulation. With constant or increasing returns to broad capital, the long-term rate of growth becomes endogenous, depending on investment decisions which, in turn, could be influenced by policies and institutions. Conditional convergence (conditional on the steady-state) implies that there is a negative partial correlation between the growth rate and the initial level of per capita income. In this context, absolute convergence is not the rule. Economies converge to a different steadystate value which depends mostly on the human capital stock and capital accumulation among other structural factors. When the underlying differences in technological progress and other factors are controlled in the convergence equation, the initial value of per capita income turns out to be strong and significantly negative. The theory predicts a faster growth for economies which have not reached their steady-state value yet.

The majority of studies provides evidence which supports the hypothesis of conditional convergence, where the initial per capita income or productivity level, the physical and human capital accumulation and innovation activities are found to be the most significant conditioning factors. In addition, R\&D activity, a sound macroeconomic environment, trade openness and well-developed financial markets contribute to raise living standards. A striking finding of these cross-country studies is that the rate of convergence runs at a very low rate of about $2 \%$ per annum. ${ }^{3}$ However, recent studies have shown that when panel data analysis is used the rate of convergence is found to be higher. ${ }^{4}$

\section{Empirical evidence on real convergence}

\section{1. $\sigma$-convergence}

The coefficient of variation is normally used to measure $\sigma$-convergence, indicating whether the asymmetries between different countries are declining through time. The coefficient of variation is given by the standard deviation of the cross-country sample divided by the sample mean. Fig. 1 plots the respective values referred to GDP per head, GDP per worker, investment share, employment ratio (as percentage of population) and unemployment rate for the period 1970-2001. The data show that unemployment is the variable where the differences between the EU-15 countries are larger and in second place is GDP per head but to a lesser extent. On the other hand, investment and employment ratios show the smallest differences.

\footnotetext{
${ }^{3}$ Temple (1999) and Soukiazis (2000) provide a theoretical survey explaining and criticising the different approaches to convergence.

${ }^{4}$ For this kind of empirical work based on panel regressions, see Islam (1995) and Bassanini and Scarpretta (2001).
} 


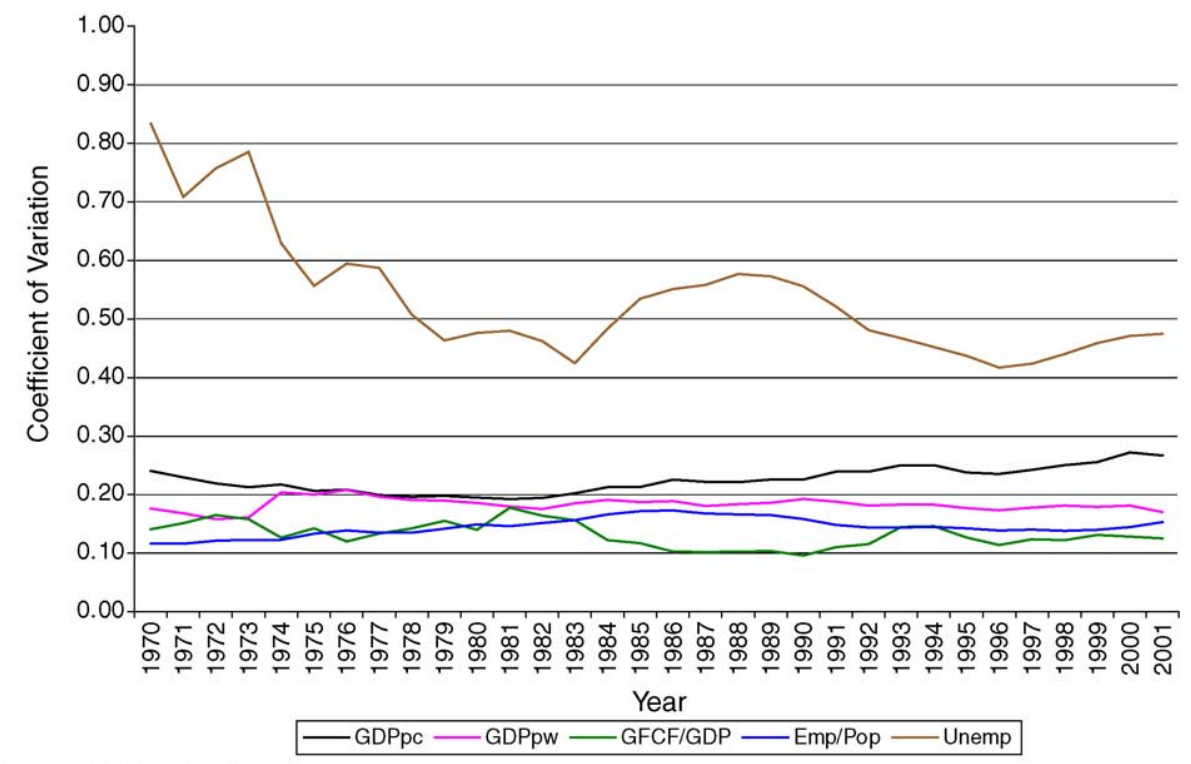

Source: OECD, Statistical Compendium, 2003.

Fig. 1. Sigma convergence by variable.

The differences in unemployment follow a more irregular path. Unemployment disparities have declined drastically from 1970 to 1983 following the higher growth performance of the majority of the EU countries, the exception being the two short periods, 1972-1973 and 1976-1977, the former related to the first oil crisis. Unemployment differences increased again from 1983 to 1988, declined afterwards up to 1996, and moved again upwards thereafter. The last period of negative performance in unemployment coincides with a tighter fiscal policy in the EU due to the Stability Pact obligations.

The differences in GDP per head also declined smoothly from 1970 to 1983, but since then the inequalities in living standards between the EU-15 countries increased moderately, especially in the post-Maastricht period. This is a rather disappointing result from the point of view of economic integration, showing that in periods of higher co-ordination of economic policies and consolidation of the single market and the creation of the monetary union, the cohesion objective of the EU is far from being achieved.

The differences in output per worker have remained almost stable during the whole period. There are no significant changes in the differences of the investment and employment ratios too.

\subsection{Per capita income convergence based on panel data regressions}

The initial specification of the convergence equation in per capita income is consistent with the standard neo-classical growth model including only the convergence factor, the 
initial level of per capita income. ${ }^{5}$ This first specification tests the hypothesis of absolute convergence, assuming that countries' per capita incomes converge to the same steadystate point. The extended model involves, additionally, the usual input factors represented by the growth of investment and labour ratios, as well as, a set of policy and institutional factors related to the Maastricht criteria, such as, public budget and debt ratios, inflation and interest rates and exchange rate variability. This augmented convergence equation is consistent with the notion of conditional convergence. ${ }^{6}$ Considering pooled cross-country time series ( $i$ denotes countries, $t$ time) the convergence equation, in its more general form, assumes the following specification:

$$
\begin{aligned}
\Delta\left(\ln y_{i, t}\right)= & a_{0}+\beta \ln y_{i, t-1}+a_{1} \mathrm{BDG}_{i, t}+a_{2} \mathrm{DBT}_{i, t}+a_{3} \mathrm{INF}_{i, t}+a_{4} \mathrm{IR}_{i, t} \\
& +a_{5} \mathrm{VER}_{i, t}+a_{6} D_{1992-2001}+a_{7} \mathrm{GK}_{i, t}+a_{8} \mathrm{GL}_{i, t}+u_{i, t},
\end{aligned}
$$

where $y$ is GDP per capita (in PPP), BDG public budget ratio, DBT public debt ratio, INF inflation rate, IR long-term interest rate, VER exchange rate annual variation, $D_{1992-2001}$ a dummy variable (takes the value of one after 1992 and zero for the years before), GK the growth of the investment ratio, GL the growth of the employment share relative to population and $u$ is the usual error term.

Table 1 reports the results obtained from the estimations of the convergence equation by using panel data for the $15 \mathrm{EU}$ countries for the period 1980-2001. The second column of Table 1 provides the results of the absolute convergence estimation by using pooling OLS estimation technique; the third column gives the results of the conditional convergence estimation following a pooling OLS procedure, and using as conditioning factors the Maastricht criteria and the growth of factor inputs; the fourth column displays the results of a panel estimation with individual intercepts to capture the specific country effects, and the last column presents the estimated results obtained from a GLS estimation, assuming that the specific country effects are random. Panel data regressions permit the use of annual data instead of averages over time, as it is often done in the cross-country empirical literature. The estimated results are rather satisfactory and give some interesting insides for the convergence process in the EU and the impact the Maastricht criteria had on income per capita performance. In all estimations it was necessary to correct first order autocorrelation by using the Maximum-Likelihood procedure. ${ }^{7}$

The coefficient of the initial per capita output variable is negative in all estimations, as expected, but with no statistical significance in the first estimation, suggesting that convergence is conditional and not absolute as the neo-classical theory assumes. Our evidence shows that conditional convergence in per capita output between the EU countries runs at a very slow annual rate (of around $2.3 \%$ in the random effects estimation, where this

\footnotetext{
${ }^{5}$ Islam (1995) and Tondl (2001) provide an analytical explanation of how to derive the convergence equation from the neo-classical production function.

${ }^{6}$ The conditional convergence equation is derived from a simple neo-classical model: $\Delta\left(\ln y_{i, t}\right)=$ $g_{t}+\beta\left(\ln y_{i, 0}^{*}-\ln y_{i, 0}\right)+\varepsilon_{i, t}$, where $\ln y_{i, 0}^{*}$ is the log level of GDP per capita on the country's steady-state path. The policy and institutional variables in the conditional convergence equation are used as proxies for differences in country steady-state GDP per capita levels $\left(\ln \mathrm{y}^{*} i, 0\right)$.

7 The regressions were made by using the econometric software package Rats 5.0.
} 
Table 1

Output per head convergence in the EU and the importance of the Maastricht criteria: panel data regressions, 1980-2001 (see Eq. (1))

\begin{tabular}{|c|c|c|c|c|}
\hline Variables & $\begin{array}{l}\text { OLS pooling } \\
\text { (absolute } \\
\text { convergence) }\end{array}$ & $\begin{array}{l}\text { OLS pooling } \\
\text { (conditional } \\
\text { convergence) }\end{array}$ & $\begin{array}{l}\text { LSDV } \\
\text { (Fixed effects) }\end{array}$ & $\begin{array}{l}\text { GLS (Random } \\
\text { effects) }\end{array}$ \\
\hline Constant & $0.0332(0.439)^{\mathrm{a}}$ & $0.273(3.35)$ & & $0.249(2.85)$ \\
\hline $\ln \left(y_{i, t-1}\right)$ & $-0.00124(-0.161)^{\mathrm{a}}$ & $-0.0256(-3.17)$ & $-0.0174(-1.44)^{\mathrm{a}}$ & $-0.023(-2.65)$ \\
\hline $\mathrm{BDG}_{i, t}$ & - & $0.0016(3.79)$ & $0.00103(2.74)$ & $0.00137(3.43)$ \\
\hline $\mathrm{DBT}_{i, t}$ & - & $0.000055(0.92)^{\mathrm{a}}$ & $-0.00012(-1.30)^{\mathrm{a}}$ & $0.000015(0.23)^{\mathrm{a}}$ \\
\hline $\mathrm{INF}_{i, t}$ & - & $-0.00145(-3.47)$ & $-0.00192(-4.56)$ & $-0.00153(-3.81)$ \\
\hline $\mathrm{IR}_{i, t}$ & - & $0.00088(1.62)^{\mathrm{a}}$ & $0.000907(1.81)^{\mathrm{a}}$ & $0.00085(1.63)^{\mathrm{a}}$ \\
\hline $\mathrm{VER}_{i, t}$ & - & $-0.000158(-0.78)^{\mathrm{a}}$ & $-0.000061(-0.30)^{\mathrm{a}}$ & $-0.00011(-0.56)^{\mathrm{a}}$ \\
\hline$D_{1992-2001}$ & - & $-0.00023(-0.073)^{\mathrm{a}}$ & $-0.00031(-0.09)^{\mathrm{a}}$ & $-0.000017(-0.05)^{\mathrm{a}}$ \\
\hline $\mathrm{GK}_{i, t}$ & - & $0.111(6.52)$ & $0.134(7.72)$ & $0.120(7.02)$ \\
\hline $\mathrm{GL}_{i, t}$ & - & $0.2039(4.81)$ & $0.247(5.74)$ & $0.226(5.36)$ \\
\hline $\begin{array}{l}\text { Half way to } \\
\text { convergence (years) }\end{array}$ & - & 26.7 & 39.4 & 29.7 \\
\hline$R^{2}$ & 0.299 & 0.504 & 0.570 & 0.487 \\
\hline$F_{1}$ & - & $6.58(0.000)$ & $6.63(0.000)$ & $6.47(0.000)$ \\
\hline$F_{2}(15,305)$ & - & - & $5.395(0.000)$ & - \\
\hline D.F. & 327 & 319 & 305 & 319 \\
\hline D.-W. & 1.95 & 2.02 & 1.95 & 1.98 \\
\hline$\rho$ & $0.541(11.08)$ & $0.412(7.02)$ & $0.148(2.20)$ & $0.294(4.72)$ \\
\hline \multicolumn{5}{|l|}{$\ln \left(y_{i, t-1}\right)$} \\
\hline Pre & $-0.0023(-0.19)^{\mathrm{a}}$ & $-0.032(-2.81)$ & $-0.035(-2.00)$ & $-0.034(-2.77)$ \\
\hline Post & $-0.0015(-0.13)^{\mathrm{a}}$ & $-0.026(-2.75)$ & $-0.017(-0.64)^{\mathrm{a}}$ & $-0.018(-2.16)$ \\
\hline \multirow{2}{*}{$\begin{array}{l}\text { Half way to } \\
\text { convergence (years) }\end{array}$} & & Pre 21.3 & Pre 19.4 & Pre 20.0 \\
\hline & & Post 26.3 & Post 40.4 & Post 38.2 \\
\hline
\end{tabular}

Notes: OLS is Ordinary Least Squares, LSDV Least Squares Dummy Variables and GLS is Generalised Least Squares methods of estimation; $D_{1}, \ldots, D_{15}$ are individual country dummies; $D_{1992-2001}$ a dummy variable to capture other economic factors not directly related to the Maastricht settings; Numbers in brackets are $t$-ratios; $F_{1}$ is used to test the joint significance of the Maastricht Criteria (significance level in parenthesis); $F_{2}$ is used to test the joint significance of the country dummy variables; D.-W. the Durbin-Watson statistic obtained after correcting autocorrelation by applying the Maximum-Likelihood procedure; and $\rho$ is the 1st order autocorrelation coefficient.

Data sources: OECD, Statistical Compendium, 2003 and European Commission, Statistical Annex of European Economy, Autumn 2002.

${ }^{a}$ Indicates that the estimated coefficient is not statistically significant at 5\% significance level.

coefficient is significant) so, it could take about 30 years to eliminate half of the differences in living standards between the EU countries.

Regarding public policy, the effect of the budget ratio is positive on the growth of per capita income and statistically significant suggesting that a reduction in public deficit is beneficial to the convergence process in Europe. However, the quantitative effect is not very strong, indicating that a one percentage point decrease in public deficit could boost output per capita growth by some $0.001-0.002$ percentage points. On the other hand, public debt seems to have no important effect on the growth of per capita income in all three estimations. 
Regarding monetary policy, inflation has the most important negative impact on the growth of per capita income, reflecting a reduction in purchasing power and a lower income performance. On the other hand, interest rate policy has not any significant effect on per capita income performance, suggesting that this policy was not growth inducing. Despite the fact that exchange rate variations influenced negatively the income per capita performance, the impacts are also not statistically significant in all cases. It is important to note (through the $F_{1}$-statistic) that the joint significance of all variables related to the Maastricht criteria is accepted in all regressions, so they cannot be ignored in the convergence equation explaining the performance of income per head.

Finally, macroeconomic policies on investment and employment influenced positively output growth performance, with the impact of employment being higher. This is an expected result since input factors related to capital and labour accumulation are important elements in explaining growth equations. The negative sign of the dummy variable, $D_{1992-2001}$, shows that the economic environment, which has been created after the imposition of the Maastricht criteria, affected negatively the European standards of living. However, this effect is not statistically significant. In order to better understand the influence of the post-Maastricht environment on the convergence process, we provide the results of the convergence coefficients obtained from two separate regressions referred to the pre- and post-Maastricht periods, 1980-1991 and 1992-2001, respectively. The evidence reported in the last row of Table $1^{8}$ are more illustrative now, suggesting that convergence in per capita output runs at a lower rate in the post-Maastricht period (less than $2 \%$ per year against more than $3 \%$ in the pre-Maastricht period) reflecting the difficulties the EU countries faced in reducing their differences in living standards once they accepted to come in line with the Maastricht requisitions. Therefore, our results suggest that it takes much more years to reduce half of the differences in per capita output in the post-Maastricht period than in the period before.

\subsection{Productivity convergence}

Output per worker is used as a proxy to measure convergence in productivity between the 15 EU countries for the period 1980-2001. The dependent variable is the growth of output per worker related to its initial level (the convergence factor) and the Maastricht criteria are introduced to measure conditional convergence in productivity. In addition, the growth of output and employment share are assumed to play an important role in explaining productivity. The inclusion of these two last variables is shown to be necessary in order to avoid error misspecification in the estimation of the convergence equation. According to Kaldor (1989) and the well known "Verdoorn Law", there is a strong statistical association between output and productivity growth, the latter being endogenously determined. An elasticity of labour productivity with respect to output less than one is an evidence of the existence of increasing returns to scale in the economies considered (known as the Verdoorn coefficient). The employment ratio is used to capture the effects of structural changes in the participation of labour as a percentage of total population. The convergence equation in

\footnotetext{
${ }^{8}$ The full results of the separate regressions are not given here because of space limitations. Full regression results are available from the authors upon request.
} 
Table 2

Output per worker convergence in the EU and the importance of the Maastricht criteria: panel data regressions, 1980-2001 (see Eq. (2))

\begin{tabular}{|c|c|c|c|c|}
\hline Variables & $\begin{array}{l}\text { OLS pooling } \\
\text { (absolute } \\
\text { convergence) }\end{array}$ & $\begin{array}{l}\text { OLS pooling } \\
\text { (conditional } \\
\text { convergence) }\end{array}$ & $\begin{array}{l}\text { LSDV } \\
\text { (Fixed effects) }\end{array}$ & $\begin{array}{l}\text { GLS } \\
\text { (Random effects) }\end{array}$ \\
\hline Constant & $0.129(1.85)^{\mathrm{a}}$ & $0.387(4.08)$ & - & $0.568(5.05)$ \\
\hline $\ln \left(p_{i, t-1}\right)$ & $-0.0105(-1.62)^{\mathrm{a}}$ & $-0.0334(-3.98)$ & $-0.11507(-7.64)$ & $-0.04858(-4.84)$ \\
\hline $\mathrm{BDG}_{i, t}$ & - & $-0.000122(-0.27)^{\mathrm{a}}$ & $0.000042(0.10)^{\mathrm{a}}$ & $-0.000182(-0.40)^{\mathrm{a}}$ \\
\hline $\mathrm{DBT}_{i, t}$ & - & $-0.00004(-0.78)^{\mathrm{a}}$ & $-0.00024(-2.58)$ & $-0.000084(-1.27)^{\mathrm{a}}$ \\
\hline $\mathrm{INF}_{i, t}$ & - & $-0.00161(-3.54)$ & $-0.00185(-3.89)$ & $-0.00163(-3.56)$ \\
\hline $\mathrm{IR}_{i, t}$ & - & $0.00106(1.78)^{\mathrm{a}}$ & $0.00027(0.50)^{\mathrm{a}}$ & $0.00075(1.26)^{\mathrm{a}}$ \\
\hline $\mathrm{VER}_{i, t}$ & - & $0.00021(0.82)^{\mathrm{a}}$ & $0.00033(1.43)^{\mathrm{a}}$ & $0.00021(0.85)^{\mathrm{a}}$ \\
\hline$D_{1992-2001}$ & - & $0.00744(2.35)$ & $0.022614(6.38)$ & $0.00996(3.06)$ \\
\hline$\Delta \ln \left(y_{i, t}\right)$ & - & $0.531(9.41)$ & $0.54073(10.0)$ & $0.52418(9.29)$ \\
\hline $\mathrm{LR}_{i, t}$ & - & $-0.0696(-2.74)$ & $-0.1891(-5.04)$ & $-0.1039(-3.47)$ \\
\hline $\begin{array}{l}\text { Half way to } \\
\text { convergence (years) }\end{array}$ & - & 20.4 & 5.7 & 13.9 \\
\hline$R^{2}$ & 0.024 & 0.305 & 0.450 & 0.306 \\
\hline$F_{1}$ & - & $2.53(0.028)$ & $3.78(0.002)$ & $2.67(0.022)$ \\
\hline$F_{2}(5,306)$ & - & - & $7.264(0.000)$ & - \\
\hline D.F. & 327 & 319 & 306 & 319 \\
\hline D.-W. & 1.96 & 2.00 & 1.89 & 2.00 \\
\hline$\rho$ & $0.136(2.39)$ & $0.162(2.84)$ & & $0.135(2.34)$ \\
\hline Haus. $x^{2}(9)$ & - & - & $5.005(0.834)$ & - \\
\hline
\end{tabular}

Notes: OLS is Ordinary Least Squares, LSDV Least Squares Dummy Variables and GLS is Generalised Least Squares methods of estimation; $D_{1}, \ldots, D_{15}$ are individual country dummies; $D_{1992-2001}$ a dummy variable to capture other economic factors not directly related to the Maastricht settings; Numbers in brackets are $t$-ratios; $F_{1}$ is used to test the joint significance of the Maastricht Criteria (significance level in parenthesis); $F_{2}$ is used to test the joint significance of the country dummy variables; D.-W. the Durbin-Watson statistic obtained after correcting autocorrelation by the Maximum-Likelihood procedure; $\rho$ the 1st order autocorrelation coefficient; Haus. $x^{2}$ is the Hausman test for random vs. fixed effects.

Data sources: OECD, Statistical Compendium, 2003 and European Commission, Statistical Annex of European Economy, Autumn 2002.

${ }^{a}$ Indicates that the estimated coefficient is not statistically significant at 5\% significance level.

productivity takes the following general form:

$$
\begin{aligned}
\Delta\left(\ln p_{i, t}\right)= & a_{0}+\beta \ln p_{i, t-1}+a_{1} \mathrm{BDG}_{i, t}+a_{2} \mathrm{DBT}_{i, t}+a_{3} \mathrm{INF}_{i, t}+a_{4} \mathrm{IR}_{i, t} \\
& +a_{5} \mathrm{VER}_{i, t}+a_{6} D_{1992-2001}+a_{7} \Delta l n y_{i, t}+a_{8} \mathrm{LR}_{i, t}+u_{i, t},
\end{aligned}
$$

where $p$ is productivity (obtained by the ratio of GDP to employment), BDG, DBT, INF, IR and VER the Maastricht criteria as defined before, $D_{1992-2001}$ the dummy variable to capture the effects of the economic conditions in the post-Maastricht period, $y$ is output per head and LR is the employment ratio. The estimation results of the convergence equations in productivity are given in Table 2 above.

The neo-classical hypothesis of absolute convergence in productivity is again rejected as the results of the second column of Table 2 show. The convergence coefficient is negative, as expected, but has no statistical significance. However, when conditional convergence 
is tested by controlling the Maastricht criteria and other structural variables, the convergence coefficient increases its magnitude and gains statistical significance (columns 3-5 of Table 2). Convergence in productivity runs by some 3-5\% per year (in the preferred estimations) suggesting that it could take 14-20 years to reduce half of the differences in productivity levels. The LSDV regression suggests a higher rate of productivity convergence at $11 \%$ per year (but this specification is rejected by the Hausman test). The joint significance of the country specific dummies $\left(F_{2}\right.$-statistic) reveals that convergence in productivity is conditional rather than unconditional.

From the monetary policy variables, inflation is the only conditioning factor affecting significantly the growth of productivity. For every one percentage point increase in inflation, productivity growth falls, on average, by 0.002 percentage points in the EU countries. The other Maastricht variables related to the ratios of public budget, public debt, interest rate and exchange rate variations do not have any significant impact on productivity growth (the exception is public debt in the LSDV estimation). Indeed, the joint effect of the policies related to Maastricht criteria (through the $F_{1}$-statistic) is not very significant.

The growth of per capita output and labour participation are important structural factors affecting significantly productivity growth in Europe. An increase of one percentage point in per capita output induces a 0.5 percentage point increase in labour productivity, reflecting increasing returns to scale characteristics. ${ }^{9}$ On the other hand, the effect of labour participation is negative on productivity growth, as expected, showing that the improvement in productivity passes necessarily from labour saving policies.

Finally, the dummy variable $D_{1992-2001}$ has a positive sign in the productivity equation and it is highly significant in all estimations. This is an evidence that the economic conditions after 1992, and the higher macroeconomic coordination achieved afterwards, may have affected positively the productivity path in Europe. However, the quantitative effect is not very strong. The Maastricht rules and higher policy coordination are responsible, on average, for less than 0.02 percentage point increase in productivity. On the other hand, from the separate estimations, it was not possible to show that productivity convergence was higher in the post-Maastricht period than the period before. ${ }^{10}$

\subsection{Convergence in investment behaviour}

The Gross Domestic Capital Formation as percentage of GDP is used to test the hypothesis of convergence in the investment ratio between the EU countries. ${ }^{11}$ The convergence equation relates the growth of investment ratio to its initial level (to test for absolute convergence) and the extended model includes the usual Maastricht criteria and the post-Maastricht dummy variable as the conditioning factors to test for conditional convergence in investment behaviour. Additionally, the growth of per capita output variable has been introduced

\footnotetext{
9 Verdoorn's Law relates the growth of labour productivity $(p)$ as a function of the growth of output $(q)$ in the single form $p=a+b q$, where $p=q-e$, with $e$ representing the growth of labour. If we substitute $p=q-e$ into the productivity function and solve with respect to $q$ we obtain, $q=\alpha+\beta e$ where $\alpha=1 / 1-b$ and $\beta=1 / 1-b$. Then, in a neoclassical production function where labour is the only input, $\beta$ gives the returns to scale result. In our case the returns to scale is around 2 , since $b=0.5$.

10 These results are not presented here but are available from the authors upon request.

${ }^{11}$ For a similar approach to the convergence in the investment ratio see Bassanini and Scarpretta (2001).
} 
Table 3

Convergence in investment behaviour between the EU countries, and the importance of the Maastricht criteria: panel data regressions, 1980-2001: $\Delta \ln I_{i, t}=a_{0}+\beta \ln I_{i, t-1}+a_{1} \mathrm{BDG}_{i, t}+a_{2} \mathrm{DBT}_{i, t}+a_{3} \mathrm{INF}_{i, t}+a_{4} \mathrm{IR}_{i, t}+$ $a_{5} \mathrm{VER}_{i, t}+a_{6} D_{1992-2001}+a_{7} \Delta \ln y_{i, t}+a_{8} \Delta \ln I_{i, t-1}+u_{i, t}$

\begin{tabular}{lcccc}
\hline Variables & $\begin{array}{l}\text { OLS pooling } \\
\text { (absolute } \\
\text { convergence) }\end{array}$ & $\begin{array}{l}\text { OLS pooling } \\
\text { (conditional } \\
\text { convergence) }\end{array}$ & $\begin{array}{l}\text { LSDV } \\
\text { (Fixed effects) }\end{array}$ & $\begin{array}{l}\text { GLS } \\
\text { (Random effects) }\end{array}$ \\
\hline Constant & $-0.156(-4.40)$ & $-0.161(-4.90)$ & - & $-0.1873(-4.72)$ \\
$\ln I_{i, t-1}$ & $-0.0976(-4.41)$ & $-0.0953(-4.57)$ & $-0.1377(-4.48)$ & $-0.1127(-4.51)$ \\
$\mathrm{BDG}_{i, t}$ & - & $0.00063(0.69)^{\mathrm{a}}$ & $0.00179(1.82)^{\mathrm{a}}$ & $0.00117(1.24)^{\mathrm{a}}$ \\
$\mathrm{DBT}_{i, t}$ & - & $0.00013(1.11)^{\mathrm{a}}$ & $0.000197(0.83)^{\mathrm{a}}$ & $0.00021(1.50)^{\mathrm{a}}$ \\
$\mathrm{INF}_{i, t}$ & - & $0.00337(3.18)$ & $0.002797(2.21)$ & $0.0034(3.17)$ \\
$\mathrm{IR}_{i, t}$ & - & $-0.00359(-2.77)$ & $-0.00462(-3.39)$ & $-0.00412(-3.15)$ \\
$\mathrm{VER}_{i, t}$ & - & $-0.00117(-2.00)$ & $-0.00145(-2.54)$ & $-0.0013(-2.27)$ \\
$D_{1992-2001}$ & - & $-0.00127(-0.20)^{\mathrm{a}}$ & $-0.01182(-1.70)^{\mathrm{a}}$ & $-0.0055(-0.85)^{\mathrm{a}}$ \\
$\Delta \ln y_{i, t}$ & - & $1.023(8.02)$ & $1.094(7.34)$ & $1.098(8.09)$ \\
$\Delta \ln \left(I_{i, t-1}\right)$ & - & $0.1325(2.68)$ & $0.0742(1.46)^{\mathrm{a}}$ & $0.10204(2.06)$ \\
Half way to & - & 6.9 & 4.6 & 5.8 \\
$\quad$ convergence (years) & & 0.352 & 0.446 & 0.395 \\
$R^{2}$ & 0.056 & $2.94(0.013)$ & $5.89(0.000)$ & $4.26(0.001)$ \\
$F_{1}$ & - & - & $5.089(0.000)$ & - \\
$F_{2}(15,291)$ & - & 305 & 291 & 305 \\
D.F. & 328 & 2.06 & 2.22 & 2.13 \\
D.-W. & 1.43 & - & $23.513(0.005)$ & \\
Haus. $x^{2}(9)$ & - & & &
\end{tabular}

Notes: OLS is Ordinary Least Squares, LSDV Least Squares Dummy Variables and GLS is Generalised Least Squares methods of estimation; $D_{1}, \ldots, D_{15}$ are individual country dummies; $D_{1992-2001}$ a dummy variable to capture other economic factors not directly related to the Maastricht settings; Numbers in brackets are $t$-ratios; $F_{1}$ is used to test the joint significance of the Maastricht Criteria (significance level in parenthesis); $F_{2}$ is used to test the joint significance of the country dummy variables; D.-W. the Durbin-Watson statistic; Haus. $x^{2}$ is the Hausman test for random vs. fixed effects.

Data sources: OECD, Statistical Compendium, 2003 and European Commission, Statistical Annex of European Economy, Autumn 2002.

${ }^{a}$ Indicates that the estimated coefficient is not statistically significant at 5\% significance level.

to represent demand forces, which is a basic argument of the accelerator principle of the Keynesian tradition. Finally, the lag-dependent variable is also used in the convergence equation to capture the effects of capital stock and to introduce more dynamics in the estimated investment equations. Table 3, reports the results obtained from the estimations of the equations used to measure convergence in investment ratios between the EU countries.

Evidence of convergence is shown in all methods of estimations, and the convergence factor is statistically significant in all cases. Conditional convergence in investment runs at a rather fast rate, approximately $10-13 \%$ per year (the Hausman test is in favour of the fixed effect estimation), suggesting that it can take 5-7 years to reduce half of the differences in investment performance between the EU countries. The joint effect of the policies related to Maastricht rules shows statistical significance $\left(F_{1}\right.$-statistic). Despite public policy related to public budget and debt has not any significant effect on investment behaviour, monetary policy has shown to be more effective in influencing investment decisions. The effect of the interest rates is negative, as it is usually expected in the investment function, but inflation 
affected positively investment behaviour. This last result can be interpreted from the supply point of view, where higher selling prices can create higher profit expectations, therefore inducing more investment. Exchange rate variability has also the expected negative effect on investment, showing that a higher risk and uncertainty resulting from currency fluctuations are not beneficial in generating higher investment, specially foreign investment. The dummy variable used to capture the effects of the post-Maastricht economic conditions have a negative sign but without statistical significance.

Finally, the income-effect on investment is highly significant being in conformity with the acceleration principle. On the other hand, the adjustment process of actual investment to desired levels is shown to be quite fast.

\subsection{Unemployment convergence}

The equation to test the convergence hypothesis in unemployment between the EU countries relates the growth of unemployment rates to its initial level (the convergence factor) and the usual Maastricht criteria as conditioning factors as well as the dummy variable to capture other economic factors reflecting the economic conditions in the postMaastricht period. The growth of the investment ratio is also included as an additional factor to capture the beneficial effects of job creation resulted from additional investment. Table 4, reports the results obtained from the estimation of the convergence equation in unemployment.

In all different methods of estimation the convergence coefficient is negative and statistically significant, as expected, revealing a higher harmonisation in unemployment performance between the EU countries for the period 1980-2001. The annual rate of unemployment convergence is about $10 \%$ (the LSDV estimation shows a higher rate), in other words, it can take about 6 years to reduce half of the differences in unemployment rates between the EU countries.

From the Maastricht criteria only public deficit influences significantly and negatively the growth of unemployment in the EU, suggesting that the effort made to reduce the public deficit was beneficial to unemployment. Our evidence shows that an annual fall in unemployment rate of about 0.01 percentage points can be explained by the restrictive fiscal policy adopted by the EU governments (deficit reduction). Meanwhile, the joint effect of all policies referred to nominal convergence is highly significant suggesting that unemployment performance in Europe was influenced significantly by the effort made of all the EU members to achieve a higher coordination of macroeconomics policies. The positive effect of the Dummy variable can be taken as evidence that the economic conditions in the post-Maastricht period were not favourable for job creation, aggravating unemployment even farther. However, the statistical significance of the Dummy variable is weak.

Finally, the negative effect of the growth of the investment ratio on unemployment is consistent with the main theoretical argument, that the increment of investment is the solution for more job creation and lowering unemployment rates. Every one percentage point increase in the growth of the investment ratio is responsible for 0.7 percentage points decrease in the growth of unemployment rates in the EU countries for the period 19802001. 
Table 4

Convergence in unemployment between the EU countries, and the importance of the Maastricht criteria: panel data regressions, 1980-2001: $\Delta \ln U_{i, t}=a_{0}+\beta \ln U_{i, t-1}+a_{1} \mathrm{BDG}_{i, t}+a_{2} \mathrm{DBT}_{i, t}+a_{3} \mathrm{INF}_{i, t}+a_{4} \mathrm{IR}_{i, t}+$ $a_{5} \mathrm{VER}_{i, t}+a_{6} D_{1992-2001}+a_{7} \Delta \ln I_{i, t}+u_{i, t}$

\begin{tabular}{lcccc}
\hline Variables & $\begin{array}{l}\text { OLS pooling } \\
\text { (absolute } \\
\text { convergence) }\end{array}$ & $\begin{array}{l}\text { OLS pooling } \\
\text { (conditional } \\
\text { convergence) }\end{array}$ & $\begin{array}{l}\text { LSDV } \\
\text { (Fixed effects) }\end{array}$ & $\begin{array}{l}\text { GLS } \\
\text { (Random effects) }\end{array}$ \\
\hline Constant & $0.265(4.94)$ & $0.144(2.77)$ & - & $0.152(2.83)$ \\
$\ln \left(U_{i, t-1}\right)$ & $-0.13936(-5.12)$ & $-0.1073(-4.80)$ & $-0.3012(-8.07)$ & $-0.1143(-4.94)$ \\
$\mathrm{BGD}_{i, t}$ & - & $-0.01441(-4.63)$ & $-0.01764(-5.42)$ & $-0.0145(-4.66)$ \\
$\mathrm{DBT}_{i, t}$ & - & $-0.0004(-0.86)^{\mathrm{a}}$ & $0.0032(3.28)$ & $-0.00033(-0.67)^{\mathrm{a}}$ \\
$\mathrm{INF}_{i, t}$ & - & $-0.00098(-0.34)^{\mathrm{a}}$ & $0.0013(0.41)^{\mathrm{a}}$ & $-0.00087(-0.29)^{\mathrm{a}}$ \\
$\mathrm{IR}_{i, t}$ & - & $0.0033(0.87)^{\mathrm{a}}$ & $0.00089(0.23)^{\mathrm{a}}$ & $0.0032(0.84)^{\mathrm{a}}$ \\
$\mathrm{VER}_{i, t}$ & - & $0.000367(0.26)^{\mathrm{a}}$ & $0.00083(0.62)^{\mathrm{a}}$ & $0.00038(0.27)^{\mathrm{a}}$ \\
$D_{1992-2001}$ & - & $0.0336(1.42)^{\mathrm{a}}$ & $0.0340(1.38)^{\mathrm{a}}$ & $0.03434(1.45)^{\mathrm{a}}$ \\
$\Delta \ln \left(I_{i, t}\right)$ & - & $-0.7819(-6.81)$ & $-0.6228(-5.62)$ & $-0.7748(-6.76)$ \\
Half way to & - & 6.1 & 2 & 5.7 \\
$\quad$ convergence (years) & & & & 0.579 \\
$R^{2}$ & 0.382 & 0.519 & $11.36(0.000)$ & $7.19(0.000)$ \\
$F_{1}$ & - & $7.07(0.000)$ & $3.588(0.000)$ & - \\
$F_{2}(15,306)$ & - & - & 1.94 & 320 \\
D.F. & 327 & 320 & $0.537(6.36)$ & $0.493(7.85)$ \\
D.-W. & 1.81 & 1.94 & $35.72(0.000)$ & \\
$\rho$ & $0.655(9.25)$ & $0.491(7.95)$ & - &
\end{tabular}

Notes: OLS is Ordinary Least Squares, LSDV Least Squares Dummy Variables and GLS is Generalised Least Squares methods of estimation; $D_{1}, \ldots, D_{15}$ are individual country dummies; $D_{1992-2001}$ a dummy variable to capture other economic factors not directly related to the Maastricht settings; Numbers in brackets are $t$-ratios; $F_{1}$ is used to test the joint significance of the Maastricht Criteria (significance level in parenthesis); $F_{2}$ is used to test the joint significance of the country dummy variables; D.-W. the Durbin-Watson statistic obtained after correcting autocorrelation by the Maximum-Likelihood procedure; $\rho$ the 1st order autocorrelation coefficient; Haus. $x^{2}$ is the Hausman test for random vs. fixed effects.

Data sources: OECD, Statistical Compendium, 2003 and European Commission, Statistical Annex of European Economy, Autumn 2002.

a Indicates that the estimated coefficient is not statistically significant at 5\% significance level.

\section{Concluding remarks}

The main purpose of the present study was to find how the Maastricht (and the late Stability and Growth Pact) restrictions affected real convergence in the EU. Indeed, the evidence from the empirical study is mixed.

Generally, we found that the Maastricht criteria cannot be ignored in growth studies since they reflect some restrictive rules in economic policy and institutional orientations. The joint effect of the Maastricht settings is significant in all cases of real convergence considered here. However, the dummy variable used as a proxy to roughly capture the post-Maastricht economic conditions shows different results depending on the variable used to measure real convergence. In the case of per capita income, despite its negative effect, the evidence is not so clear because of lack of statistical significance. Nevertheless, the separate estimations of the pre- and post-Maastricht periods show that convergence in per capita income runs 
at a slower rate in the latter period, precisely when member countries decided to realign their economic policy with the Maastricht requisitions. This result is consistent with recent discussions on European policy reclaiming a more flexible Stability and Growth Pact, which takes into account specific country problems.

On the contrary, we found that the post-Maastricht period influenced positively the convergence process in productivity in the EU, despite its quantitative effect being small. The influence of the Maastricht period was negative on investment and unemployment, but the statistical significance of the dummy variable was weak.

The individual influence of the variables associated to the Maastricht criteria is also mixed in the different estimated equations. Public budget (with a positive effect) and inflation (with a negative effect) had the most significant influence on the growth of per capita income. Inflation was the only variable of the Maastricht settings that influenced (negatively) the growth of labour productivity. The case of investment shows a different picture. Public settings (budget and debt) had no significant influence on capital accumulation, but monetary settings had. Interest rates and exchange rate variations influenced negatively investment behaviour, as expected, but inflation had an unexpected positive influence. Finally, public budget was the only variable related to the Maastricht criteria that influenced significantly (negatively) the unemployment performance. Our evidence suggests that the effort that has been made to reduce public deficit was beneficial in reducing unemployment in the EU. However, this result has to be interpreted with caution for two reasons: firstly, the specific country effects are shown to be different from country to country; and secondly, it can exist a bias due to a twofold effect between unemployment and public deficit. Thus, further research is needed in order to test a possible reverse causality.

Conditioning factors (along with the Maastricht criteria) are all important in the estimated equations, solving the problem of omitted variable misspecification. Input factors associated to capital and labour growth are important variables in explaining the growth of per capita income, having the expected positive elasticities. Output growth (with a positive effect) and labour participation (with a negative effect) are shown to be important structural factors in explaining productivity growth. Productivity elasticity with respect to output confirms the existence of increasing returns to scale properties being in line with the Verdoorn's Law findings. The negative elasticity of productivity with respect to labour participation shows that the improvement in productivity passes necessarily from labour saving policies. The accelerator principle and the stock adjustment mechanism of the Keynensian tradition are strongly confirmed in the estimation of the investment equation. Finally, the growth of investment contributes significantly in the reduction of unemployment.

Our evidence also shows that convergence is conditional rather than absolute, especially in the case of output per head and output per worker. The degree of explanation of the estimated convergence equations improves substantially when the conditioning factors are introduced (structural and Maastricht settings) and the convergence coefficient increases its magnitude. Convergence in per capita output runs at a very small annual rate confirming the basic rule of $2 \%$ convergence rate of the Sala-i-Martin (1996) findings in the cross section studies. The relative homogeneity of the EU countries may be the main explanation why the convergence in per capita output is smaller than in other studies considering a less homogeneous set of countries (for instance, Islam (1995) and Bassanini and Scarpretta (2001)). 
In conclusion, this study shows that the Maastricht rules and the Stability and Growth Pact have not been so significant as the European authorities would expect and even in cases where the Maastricht criteria had positive effects, these were modest. In this context, the European monetary authorities have to allow for a more flexible fiscal policy that takes into account countries' specificities and the economic cycle position in order to national countries achieve a higher real convergence.

\section{Acknowledgments}

We would like to thank Eric J. Pentecost for helpful comments and suggestions and other participants in the EEFS conferences at Gdansk (May 2004) as well as two anonymous referees.

\section{References}

Bassanini, A., \& Scarpretta, S. (2001). The driving forces of economic growth: Panel data evidence for the OECD countries. OECD Economic Studies, 33(II), 9-56.

Barro, R. (1991). Economic growth in a cross section of countries. Quarterly Journal of Economics, 106(May), 407-501.

Chatterji, M. (1992). Convergence clubs and endogenous growth. Oxford Review of Economic Policy, 8(4), 57-69.

Islam, N. (1995). Growth empirics: a panel data approach. Quarterly Journal of Economics, 110(4), 1127-1170.

Kaldor, N. (1989). Causes of the slow rate of economic growth of the United Kingdom. An inaugural lecture. In F. Targetti \& A. P. Thirlwall (Eds.), The Essential Kaldor. Cambridge University Press.

Sala-i-Martin. (1996). Regional cohesion: Evidence and theories of regional growth and convergence. European Economic Review, 40, 1325-1352.

Sala-i-Martin. (2003). Keynotes speech: Convergence and divergence-Theoretical underpinning. In G. TumpelGugerell \& P. Mooslechner (Eds.), Economic Convergence and Divergence in Europe. Edward Elgar Publishing.

Solow, R. (1956). A contribution to the theory of economic growth. Quarterly Journal of Economics, (February).

Soukiazis, E. (2000). What we have learnt about convergence in Europe? Some theoretical and empirical considerations. Discussion paper no. 2. CEUNEUROP, Faculty of Economics, University of Coimbra, Portugal.

Temple, J. (1999). The new growth evidence. Journal of Economic Literature, XXXVII(March), 112-156.

Tondl, G. (2001). Convergence after Divergence? Regional growth in Europe. New York: Springer, Verlag, Wien. 